\title{
Effects of the visual pollution in Intramuros: Basis for heritage preservation
}

\author{
Marcelo, Jefferson $\bowtie$ \\ Taguig City University, Philippines (jeffersonmarcelo119@gmail.com) \\ Parco, Eunice G. \\ Taguig City University, Philippines (euniceparco@gmail.com) \\ Coniendo, Creslie Kim S. \\ Taguig City University, Philippines (cresliekimconiendo17@gmail.com)
}

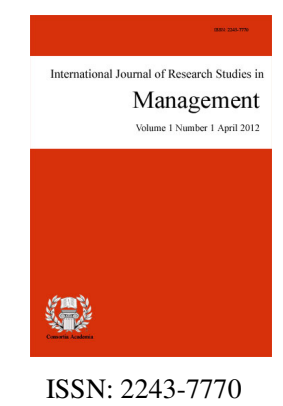

Gomez, Ma Luisa

Taguig City University, Philippines (maluisagomez13@gmail.com)

Amutan, Shirley Y.

Taguig City University, Philippines (shiesymon@gmail.com)

Received: 10 July $2021 \quad$ Revised: 28 September $2021 \quad$ Accepted: 6 October 2021

Available Online: 8 October $2021 \quad$ DOI: $10.5861 /$ ijrsm.2021.m7727

\section{Abstract}

Heritage sites are arguably the physical component of a city's identity. The lived-in architecture, the strategic locations and the uses of these buildings reveal unique stories telling of how our city came to be and can offer predictions of where it might be going. One of the hindrances of preserving, an architectural heritage is a modernization of the place, or most likely is the visual pollution. Visual pollution does not only destroy heritage attractions but it also affects human's state of calmness from these views which supposed to calm and relaxes the mind like how nature does. This research focuses on the "Effects of Visual Pollution in Intramuros: Basis for Heritage Preservation". Its objective is to preserve the architectural heritage of our country particularly in walled city or the Intramuros by specifically analyzing the effects of visual pollution. The researchers also believed that this study could contribute on how to preserve these heritage sites, and keep Intramuros as one of the 12 worldwide sites according to the GHF or Global Heritage Fund. This study employed the descriptive method of research to determine the effects of visual pollution in Intramuros and the findings were used as basis for heritage preservation. The researchers sampling techniques was non-probability, where they took a part of a whole. In relation to this, non-probability will be used as the sampling technique for this research study. Conclusion and recommendation have been formulated for the study particularly in the implementation of projects and activities of the Intramuros Administration supported by the Department of Tourism.

Keywords: heritage, preservation, visual pollution, sustainability, Intramuros, partnership 


\section{Effects of the visual pollution in Intramuros: Basis for heritage preservation}

\section{Introduction}

Preserving heritage sites can sustain the culture and tell the story of a place if these sites can sustain the aesthetic of its community not just for culture but also boosts tourism. In preserving our heritage, we preserve our identity. Heritage sites are arguably the physical component of a city's identity. The lived-in architecture, the strategic locations and the uses of these buildings reveal unique stories telling of how our city came to be and can offer predictions of where it might be going. These features add character and beauty to our city, fostering a sense of home and community, and serving as a reminder to each of us that our city's history belongs to all of us together.

Heritage sites circulate wealth within the local economy. Visiting heritage sites would take someone walk in the past. People would claim they were taken back in old times. These are mostly enjoyed with the sites marketing aisles that also adds up to the feeling of being in the past. Most people find this relaxing. It cannot be denied that as people's lives improve, heritage sites are sometimes neglected to keep its value.

Modernity is taking Filipino streets on its new form where sites no longer tell histories because of visual pollution. Visual pollution means contaminating the atmosphere though extra ordinary visual. It can be through formal settler, illegal parking, and graffiti on the walls like posters, billboards, brochure, pamphlets; posters are pastes on the walls of houses and shops without the dispensation of owners. Visual pollution does not only destroy heritage attractions but it also affects human's state of calmness from these views which supposed to calm and relaxes the mind like how nature does. Visual pollution is an aesthetic issue and refers to the impact of Pollution that impair one's ability to enjoy a vista or view. It disturbs the visual areas of people by creating negative changes in the natural environment. Open storage of trash, space debris, telephone towers, electric wires, buildings and automobiles are forms of visual pollution.

An overcrowded area causes visual pollution. Effects of visual pollution include distraction, eye fatigue, decreases in option diversity, and loss of identity. Manila was the key trade center in the Philippines during the15th century. The Spaniards needed to protect Filipinos from foreign invaders during the era of colonialism by building the "Intramuros" (Spanish word for "within the wall"). Intramuros has been devastated by battles, fires, and earthquakes but has survived the test of time. It holds bittersweet memories of the colonial past, a heritage worth preserving and sharing with the world.

Barroga et al. (2020) concluded in their study that it was able to define visual pollution - and similarly, visual pollutants, as elements of the landscape that do not conform with the surrounding elements, and is unable to collaborate with the character of the built environment. These elements do not blend in with the context of the place, which causes the existing environment to degrade and become unpleasant to its residents. The viewers are the ones capable of distinguishing whether such elements are visual pollutants or not, as it relies on shared visual preferences. The indirect and direct methods were able to assess the visual pollution present in the landscapes of Intramuros. It was able to yield the Landscape Attribute Inventory, Response Ratings, and Interview results and insights. These series of methods were able to translate visual characteristics into measurements. Data results after analysis were able to establish the equation in calculating the visual pollution score. Through this methodology, the goal of identifying, analyzing, and measuring visual pollution in Intramuros was realized. There are 8 of the 22 landscape codes, which subsequently consists of 14 of the 30 total viewpoints, are considered to be visually-polluted. Electric posts, cable wires, and settlements that use a mishmash of indigenous materials identified as visual blight by the interviewed professionals were common elements in the unacceptably visually polluted viewpoints. While the presence of the identified visual blight in landscapes may indicate a higher visual pollution score, the presence and absence of key indicators Complexity, Disturbance, Imageability, 
and Stewardship were able to specify which are and are not unacceptably visually polluted. It is also important to note that the indicators Complexity, Disturbance, and Imageability rely on the elements of the landscape and the coherence of their style and aesthetic with each other, which is why the presence of the identified visual blight do not automatically indicate that a viewpoint is unacceptably visually-polluted. As for the present Intramuros, informal settlers occupied several areas and many pedicab or cycle rickshaws as it is called in other nations, are congested inside the so-called "within the walls." Some of the street around Muralla Street, Sta. Lucia Street, Arzobispo Street and Maestranza Street have been observed that was built with many fast-food franchises, children who are begging for food and money, car parks in every street you can sight of. This scrutiny of the present Intramuros is affecting the cultural heritage value of the place that may cause to lost its identity.

This research focuses on the "Effects of Visual Pollution in Intramuros: Basis for Heritage Preservation". Its objective is to preserve the architectural heritage of our country particularly in walled city or the Intramuros. The researchers also believed that this study could contribute on how to preserve these heritage sites, and keep Intramuros as one of the 12 worldwide sites according to the GHF or Global Heritage Fund.

\subsection{Objective of the Study}

The study has the following objectives which are (1) to identify the possible effects of visual pollution in the tourists and community (2) to protect the welfare and sustainability of Intramuros (3) to preserve the heritage and identity of the old city which inherited by the Spanish colonial in our country (4) to promote the Philippine culture that will utilize by tourists and community for the next generation and the government of economic would be benefited (5) and to disseminate the value of how important the heritage site to our county.

\section{Methods}

This study employed the descriptive method of research to determine the effects of visual pollution in Intramuros and the findings were used as basis for heritage preservation. According to Watson (2015), quantitative research is a term that refers to the collection of techniques for systemically investigating social phenomena using statistical or numerical data. It aims to look for patterns and relationships in data and to double-check the measurements made. It attempted to answer the profile of the tourists (local and international) respondents in terms of their age, sex, nationality, civil status and years of residence. It also answered the assessment of the respondents on the effects of visual pollution in terms of (a) identify, (b) protect, (c) preserve, (d) promote, (e) disseminate. The researchers would like to allow the readers to recognize the potential factor that causes visual pollution in Intramuros.

The researchers sampling techniques was non-probability, where they took a part of a whole. In relation to this, non-probability will be used as the sampling technique for this research study. It is characterized as a sampling technique in which samples are chosen based on the researcher's subjective judgment rather than random selection. To achieve the sample size, the researchers used the purposive sampling technique because the selected residents of Intramuros district and selected tourists (local and international) are the respondents who are covered inside Intramuros Manila.

The respondents of this study were the residents of Intramuros, Manila and selected tourists (local and international) of Metro Manila with the total of one hundred (100) respondents composed of fifty (50) residents of Intramuros, Manila, forty (40) local tourists, and ten (10) international tourists.

The researcher gathered the data by administering the questionnaire to the tourists who are visiting Intramuros and the residents as well in the street boundaries around Muralla Street, Sta. Lucia Street, Arzobispo Street and Maestranza Street. The data were collected after the one hundred (100) respondents have answered the questionnaire. The researcher retrieved the answered questionnaires, tallied the responses, tabulated, and computed the data that has been gathered with the statistician. Certain statistical tools were utilized by the researchers to determine the insights of the tourists (local and international) who visited Intramuros and the 
Marcelo, J., Parco, E. G., Coniendo, C. K. S., Gomez, M. L., \& Amutan, S. Y.

residents as well in the street boundaries around Muralla Street, Sta. Lucia Street, Arzobispo Street and Maestranza Street. The answers to the questionnaire were analyzed by tallying. Percentage Distribution, Weighted Mean, and Pearson Correlation for testing the relationship of the variables has been used in the research paper. Lastly, the researcher presented the data in textual and tabular forms with due consideration on the sub-problems and hypotheses of the research study.

\section{Results and Discussion}

\section{Table 1}

Frequency and Percentage Distribution Profile of the Respondents

\begin{tabular}{|c|c|c|}
\hline Age & Frequency & Percentage \\
\hline 19 years old and below & 15 & $15 \%$ \\
\hline 20 - 30 years old & 66 & $66 \%$ \\
\hline 31 - 40 years old & 15 & $15 \%$ \\
\hline $41-50$ years old & 3 & $3 \%$ \\
\hline 50 and above & 1 & $1 \%$ \\
\hline Sex & Frequency & Percentage \\
\hline Male & 54 & $54 \%$ \\
\hline Female & 46 & $46 \%$ \\
\hline Nationality & Frequency & Percentage \\
\hline Filipino & 90 & 90 \\
\hline Others: Indian, Vietnamese, Chinese, Korean, American, German & 10 & 10 \\
\hline Civil Status & Frequency & Percentage \\
\hline Single & 83 & 83 \\
\hline Married & 8 & 8 \\
\hline Separated & 8 & 8 \\
\hline Widowed & 1 & 1 \\
\hline
\end{tabular}

Table 1 illustrates the frequency and percentage distribution profile of the respondents by age. Ages $20-30$ years old get the greatest number of respondents gaining frequency of 66 or $66 \%$, ages 19 years old and below and $31-40$ years old ties at the frequency of 15 or $15 \%$ followed by ages $41-50$ years old with a frequency of 3 or $3 \%$; and lastly, ages 50 and above is with the least number of respondents gaining a frequency of 1 or $1 \%$. Most of the respondents are born in 90's where they indicate the love to travel to free themselves from stress as they want to bring back the time as how it is like before. While, out of one hundred (100) respondents are 54 or $54 \%$ whose sex belongs to Male; 46 or $46 \%$ belongs to Female. Most of the respondents are male.

Table also indicates the nationality of the respondents, which consist of 90 or $90 \%$, are Filipinos they are the local tourists and residents in Intramuros district. Quite a number of international tourists are 10 or $10 \%$ other nationality such as Indian, Vietnamese, Chinese, Korean, American, German. The distribution of respondents according to civil status, as shown in the table above implies that the majority 83 or $83 \%$ are tourists (local and international) and the residence are single, and 8 or $8 \%$ are married and separated are tied. There are only few 1 or $1 \%$ widowed.

Table 2

Mean Distribution of Identity Factors

\begin{tabular}{|c|c|c|c|c|c|c|c|}
\hline \multirow{2}{*}{ Identify Factors } & \multicolumn{2}{|c|}{ Residents } & \multicolumn{2}{|c|}{ Local Tourists } & \multicolumn{2}{|c|}{ Foreign Tourists } & \multirow{2}{*}{$\mathrm{R}$} \\
\hline & M & VI & $\mathrm{M}$ & VI & M & VI & \\
\hline 1. Illegal parking in the streets of Intramuros. & 2.88 & A & 2.83 & A & 3.50 & SA & 3 \\
\hline 2. Improper solid waste disposal in Intramuros. & 2.84 & A & 2.73 & A & 3.10 & A & 5 \\
\hline 3. Improper installation of wires in Intramuros. & 3.04 & A & 2.50 & A & 3.60 & SA & 4 \\
\hline 4. Graffiti as an act of vandalism in Intramuros. & 2.98 & A & 2.95 & A & 3.40 & A & 2 \\
\hline 5. The community in Intramuros has lack of discipline. & 3.12 & A & 2.80 & A & 3.60 & SA & 1 \\
\hline Overall Mean & 2.97 & A & 2.76 & A & 3.44 & A & \\
\hline
\end{tabular}

Legend: $3.50-4.00=$ Strongly Agree (SA), $2.50-3.49=$ Agree(A), $1.50-2.49=$ Disagree(D), $1.00-1.49=$ Strongly Disagree (SD); $\mathrm{M}=$ Mean; V.I = Verbal Interpretation; R=Rank. 
Table 2 shows the mean of identify factors. The respondents highly agree with an overall mean of 3.06. In particular, the community in Intramuros lack discipline with a mean of 3.17 and ranks as 1 followed by graffiti as an act of vandalism in Intramuros with a mean of 3.11 that ranks as 2; Illegal parking in the streets of Intramuros with a mean of 3.07 and ranks as 3; improper installation of wires in Intramuros with a mean of 3.05 and ranks as 4; and finally, Improper solid waste disposal in Intramuros with a mean of 2.89 and it ranks as 5.

According to Prompayuk and Chairatananonda (2017) often found that the heritage buildings and surroundings are carefully preserved while the way of life and socio-economic structure are not. On the other hand, this is not the same in developed countries. Therefore, this study aimed to investigate the method of successful cultural heritage community preservation in those states. The conclusion is that, in order to preserve this heritage successfully, the preservation method must have an establishment of organizations that effected changes and systematic management procedures for maintenance.

Table 3

Mean Distribution of Safety Factors

\begin{tabular}{|c|c|c|c|c|c|c|c|}
\hline \multirow{2}{*}{$\begin{array}{l}\text { Identify Factors } \\
\text { Intramuros Administration... }\end{array}$} & \multicolumn{2}{|c|}{ Residents } & \multicolumn{2}{|c|}{ Local Tourists } & \multicolumn{2}{|c|}{ Foreign Tourists } & \multirow{2}{*}{$\mathrm{R}$} \\
\hline & M & VI & M & VI & M & VI & \\
\hline 1. lack of maintenance. & 3.04 & A & 2.93 & A & 3.50 & $\mathrm{SA}$ & 3 \\
\hline 2. lack of security personnel. & 2.96 & A & 3.00 & A & 3.30 & A & 4 \\
\hline 3. lack of restriction. & 3.12 & A & 2.97 & A & 3.60 & SA & 1 \\
\hline 4. lack of ordinance in visual pollution. & 3.10 & A & 3.13 & A & 3.33 & A & 2 \\
\hline 5. lack of signposts. & 2.96 & A & 2.80 & A & 3.40 & A & 5 \\
\hline Overall Mean & 3.04 & A & 2.97 & A & 3.43 & A & \\
\hline
\end{tabular}

Table 3 shows the mean safety factors. The respondents highly agree with an overall mean of 3.14. Specifically, the Intramuros Administration lacks of restriction with a mean of 3.23 and ranks as 1 followed by Intramuros Administration who lacks of ordinance in visual pollution with a mean of 3.19 and ranks as 2; Intramuros Administration's lack of maintenance with a mean of 3.16 and ranks as 3 then Intramuros Administration's lack of security personnel with a mean of 3.09 and ranks as 4; and finally, Intramuros Administration's lack of signposts with a mean of 3.05 and ranks as 5 .

Table 4

Mean Distribution of Preserve Factors

\begin{tabular}{|c|c|c|c|c|c|c|}
\hline \multirow{2}{*}{ Preserve Factors } & \multicolumn{2}{|c|}{ Resident/s } & \multicolumn{2}{|l|}{ Local } & \multicolumn{2}{|c|}{ Foreign } \\
\hline & M & VI & $\mathrm{M}$ & VI & $\mathrm{M}$ & VI \\
\hline 1. Possible modernization in Intramuros. & 3.22 & A & 2.70 & A & 3.50 & SA \\
\hline 2. Intramuros has many infrastructures. & 3.14 & A & 3.17 & A & 3.50 & SA \\
\hline 3. No designated place for vendors in Intramuros. & 2.94 & A & 3.20 & A & 3.50 & SA \\
\hline 4. Increasing of establishments in Intramuros. & 3.30 & A & 2.97 & A & 3.50 & SA \\
\hline $\begin{array}{l}\text { 5. Intramuros Administration did not prioritize the preservation of the } \\
\text { city inside the wall. }\end{array}$ & 3.28 & A & 3.10 & A & 3.30 & A \\
\hline Overall Mean & 3.18 & A & 3.03 & A & 3.46 & A \\
\hline
\end{tabular}

Legend: $3.50-4.00=$ Strongly Agree (SA), $2.50-3.49=$ Agree(A), $1.50-2.49=$ Disagree(D), $1.00-1.49=$ Strongly Disagree (SD); $\mathrm{M}=$ Mean; V.I = Verbal Interpretation; R=Rank.

The table above shows that the ranking of recommendation for preserve factors. The respondents highly agree with an overall mean of 3.22. In particular, the Intramuros has many infrastructures with a mean 3.27 and ranks as 1 followed by Increasing of establishments in Intramuros with a mean of 3.26 and ranks as 2 ; Intramuros Administration did not prioritize the preservation of the city inside the wall with a mean of 3.23 and ranks as 3 No designated place for vendors in Intramuros with a mean of 3.21 and ranks as 4; and finally, Possible modernization in Intramuros with a mean of 3.14 and ranks as 5. Dumcke et al., (2015) strongly believe that it should be recognized to review the social and economic value of cultural heritage is part of broader debate of the valuation of cultural goods within the cultural economy because in recent years the economic value of cultural heritage has been more extensively. In Intramuros it has church, park, museum, private sectors, and 
Marcelo, J., Parco, E. G., Coniendo, C. K. S., Gomez, M. L., \& Amutan, S. Y.

school that will utilize for researchers, students project, school tour. People can unwind and it can good for family and friends as well.

\section{Table 5}

Mean Distribution of Promote Factors

\begin{tabular}{|c|c|c|c|c|c|c|c|}
\hline \multirow{2}{*}{ Promote Factors } & \multicolumn{2}{|c|}{ Resident/s } & \multicolumn{2}{|c|}{ Local Tourists } & \multicolumn{2}{|c|}{ Foreign Tourists } & \multirow[t]{2}{*}{$\mathrm{R}$} \\
\hline & M & VI & M & VI & $\mathrm{M}$ & VI & \\
\hline 1. The cleanliness in the streets is a must. & 3.60 & SA & 3.75 & SA & 3.60 & SA & 1 \\
\hline $\begin{array}{l}\text { 2. Provide livelihood program in the } \\
\text { community in Intramuros. }\end{array}$ & 3.56 & SA & 3.65 & SA & 3.50 & SA & 4 \\
\hline $\begin{array}{l}\text { 3. The importance of the marginalized } \\
\text { workers in Intramuros. }\end{array}$ & 3.44 & A & 3.65 & SA & 3.40 & A & 5 \\
\hline $\begin{array}{l}\text { 4. Offering a painting activity in the } \\
\text { community that could help them to discover } \\
\text { their talent in art. }\end{array}$ & 3.60 & SA & 3.62 & SA & 3.50 & SA & 3 \\
\hline $\begin{array}{l}\text { 5. Conducting a seminar about the proper } \\
\text { waste disposal in Intramuros. }\end{array}$ & 3.60 & SA & 3.72 & SA & 3.50 & SA & 2 \\
\hline Overall Mean & 3.56 & SA & 3.68 & SA & 3.50 & SA & - \\
\hline
\end{tabular}

Table 5 reveals the mean of promote factors. The respondents highly agree with an overall mean of 3.58 . Particularly, The cleanliness in the streets is a must with a mean 3.65 which ranks as 1 followed by Conducting a seminar about the proper waste disposal in Intramuros with a mean of 3.61 and rank as 2; Offering a painting activity in the community that could help them to discover their talent in art with a mean of 3.57 as rank 3 it is higher than rank 4 for .1 Provide livelihood program in the community in Intramuros with a mean of 3.57 and it is rank as 4; and finally The importance of the marginalized workers in Intramuros with a mean of 3.14 with a rank of 5. According to Szczepańska et al. (2019) they determine the scale of visual pollution in a protected area - trends in the location, size, form and influence on the surroundings and perception. In both analyzed countries there are regulations that would not bring the desired effects regarding the advertising policy. Advertisement devices are present in settlements and at significant road points, entrances to facilities connected with tourism. A point of concern is that they are frequently placed in the most precious landscape areas.

Table 6

Mean Distribution of Disseminate Factors

\begin{tabular}{|c|c|c|c|c|c|c|c|}
\hline \multirow{2}{*}{ Disseminate Factors } & \multicolumn{2}{|c|}{ Resident/s } & \multicolumn{2}{|c|}{ Local } & \multicolumn{2}{|c|}{ Foreign } & \multirow[t]{2}{*}{$\mathrm{R}$} \\
\hline & $\mathrm{M}$ & VI & $\mathrm{M}$ & VI & M & VI & \\
\hline 1. Information policy of Intramuros Administration. & 3.50 & SA & 3.57 & SA & 3.20 & A & 5 \\
\hline $\begin{array}{l}\text { 2. Safety reminder in the street of Intramuros } \\
\text { Administration. }\end{array}$ & 3.51 & SA & 3.70 & SA & 3.60 & SA & 2 \\
\hline $\begin{array}{l}\text { 3. Knowledgeable about ordinance of visual pollution of } \\
\text { the Intramuros Administration. }\end{array}$ & 3.54 & SA & 3.57 & SA & 3.40 & A & 4 \\
\hline $\begin{array}{l}\text { 4. Giving the public notice to the tourists and community in } \\
\text { Intramuros. }\end{array}$ & 3.54 & SA & 3.70 & SA & 3.40 & A & 3 \\
\hline $\begin{array}{l}\text { 5. Providing the historical or cultural information about in } \\
\text { Intramuros. }\end{array}$ & 3.64 & SA & 3.80 & SA & 3.40 & A & 1 \\
\hline $\begin{array}{ll}\text { Overall Mean } \\
\end{array}$ & 3.55 & SA & 3.67 & SA & 3.40 & A & - \\
\hline
\end{tabular}

Table 6 shows the mean of disseminate factors. The respondents highly agree with an overall mean of 3.54. Distinctly, Providing the historical or cultural information about in Intramuros with a mean 3.61 and ranks as 1 followed by Safety reminder in the street of Intramuros Administration with a mean of 3.60 and ranks as 2; Giving the public notice to the tourists and community in Intramuros with a mean of 3.55 and ranks as 3 knowledgeable about ordinance of visual pollution of the Intramuros Administration with a mean of 3.50 and ranks as 4; and finally, Information policy of Intramuros Administration with a mean of 3.42 and ranks as $5^{\text {th }}$. Jana, (2015), discussed the effects of exposure to visual pollution may be vast and penetrating. They include: 
distraction, decreases in opinion diversity, and loss of identity. Healthy visual environment promotes the values of those who live there, promotes civic pride and economic health of the community because all human beings are part of natural environment. The inhabitants show an innate instinct to experience a good feeling when integrated with the beautiful Nature, which is reflected in the opinion of the respondents that they would prefer to visit to the pleasant picturesque places of natural beauty free from visually unpleasant sight to re-energize and relieve stress.

Table 7

Significant relationship between the Nationality and Identify Factors

\begin{tabular}{lcll}
\hline \multicolumn{1}{c}{ Interrelationship } & $\mathrm{p}$ - value & \multicolumn{1}{c}{ Decision } & \multicolumn{1}{c}{ Interpretation } \\
\hline Residents & .061 & Accepted & Not Significant \\
Local Tourists & .434 & Accepted & Not Significant \\
Foreign Tourists & .030 & Accepted & Significant \\
\hline Note: if the computed p-value is greater than the level of significant, which is 0.05, it accepts the null hypothesis. Otherwise, rejects.
\end{tabular}

The finding suggests that the computed p-value of residents (.061) and local tourists (.434) which means that the null hypothesis is accepted. That is, at the 0.05 level of significant, there is no significant relationship between the assessment of the respondents on the effects of visual pollution and nationality. However, the computed p-value of foreign tourists (.030) is less than the level of significance, which is 0.05 ; it means that the null hypothesis is rejected. The tourism has been one of the most widely disseminated social and economic phenomena since World War II. Visual pollution can also refer to visibility issues such as when a distant scenic view is blocked by an unattractive element in the landscape. Graffiti, spray-painted names and messages are a form of urban visual blight. This type of vandalism and its eradication in cities and towns can cost a lot of taxpayers' money. It means that the weather of the quality of the attraction, services, locals, views and other facilities are affecting the level satisfaction of one's tourist. This is further supported by Lloren, (2015) who stated that the classical aesthetic point-of-view, the beauty of the past is measured in proportion, by the discipline of ordered arrangements, symmetry and harmonious content. The community and tourists should keep their discipline while visiting the city of our ancestors "Intramuros" by avoiding vandalism, illegal parking, and proper solid waste disposal to preserve the heritage. That could benefit for the youth the future generation.

\section{Table 8}

Significant relationship between the Nationality and Safety Factors

\begin{tabular}{llll}
\hline \multicolumn{1}{c}{ Interrelationship } & $\mathrm{p}$ - value & Decision & Interpretation \\
\hline Residents & .085 & Accepted & Not Significant \\
Local Tourists & .225 & Accepted & Not Significant \\
Foreign Tourists & .059 & Accepted & Not Significant \\
\hline Note: if the computed p-value is greater than the level of significant, which is 0.05, it accepts the null hypothesis. Otherwise, rejects.
\end{tabular}

The table 8 illustrates that the computed p-value of residents (.085), local tourists $(.225)$ and foreign tourists (.059) which means that the null hypothesis is accepted. That is, at the 0.05 level of significant, there is no significant relationship between the assessment of the respondents on the effects of visual pollution and nationality.

Table 9

Significant relationship between the Nationality and Preserve Factors

\begin{tabular}{llll}
\hline \multicolumn{1}{c}{ Interrelationship } & $\mathrm{p}$ - value & Decision & \multicolumn{1}{c}{ Interpretation } \\
\hline Residents & .074 & Accepted & Not Significant \\
Local Tourists & .264 & Accepted & Not Significant \\
Foreign Tourists & .074 & Accepted & Not Significant \\
\hline Note: if the computed p-value is greater than the level of significant, which is 0.05, it accepts the null hypothesis. Otherwise, rejects.
\end{tabular}

The table 9 reveals that the computed p-value of residents (.074), local tourists (.264) and foreign tourists (.074) which means that the null hypothesis is accepted. That is, at the 0.05 level of significant, there is no 
Marcelo, J., Parco, E. G., Coniendo, C. K. S., Gomez, M. L., \& Amutan, S. Y.

significant relationship between the assessment of the respondents on the effects of visual pollution and nationality.

\section{Table 10}

Significant relationship between the Nationalities on Promote Factors

\begin{tabular}{lcll}
\hline \multicolumn{1}{c}{ Interrelationship } & $\mathrm{p}$ - value & Decision & \multicolumn{1}{c}{ Interpretation } \\
\hline Residents & .972 & Accepted & Not Significant \\
Local Tourists & .854 & Accepted & Not Significant \\
Foreign Tourists & .920 & Accepted & Not Significant \\
\hline Note: if the computed p-value is greater than the level of significant, which is 0.05 , it accepts the null hypothesis. Otherwise, rejects.
\end{tabular}

The table 10 unfolds that the computed p-value of residents (.972), local tourists (.854) and foreign tourists (.920) which means that the null hypothesis is accepted. That is, at the 0.05 level of significant, there is no significant relationship between the assessment of the respondents on the effects of visual pollution and nationality.

\section{Table 11}

Significant relationship between the Nationality on Disseminate Factors

\begin{tabular}{lccl}
\hline \multicolumn{1}{c}{ Interrelationship } & p- value & Decision & Interpretation \\
\hline Residents & .175 & Accepted & Not Significant \\
Local Tourists & .691 & Accepted & Not Significant \\
Foreign Tourists & .513 & Accepted & Not Significant \\
\hline Note: if the computed p-value is greater than the level of significant, which is 0.05, it accepts the null hypothesis. Otherwise, rejects.
\end{tabular}

The table 11 reveals that the computed p-value of residents (.175), local tourists (.691) and foreign tourists (.513) which means that the null hypothesis is accepted. That is, at the 0.05 level of significant, there is no significant relationship between the assessment of the respondents on the effects of visual pollution and nationality.

\section{Conclusion and Recommendation}

Visual pollution can also refer to visibility issues such as when a distant scenic view is blocked by an unattractive element in the landscape. Graffiti, spray-painted names and messages are a form of urban visual blight. The rank and recommendation that effects preserving the heritage of Intramuros is that the community in Intramuros lacked discipline in terms of identify factors, second is followed by the graffiti which was seen as an act of vandalism in Intramuros, third was the Illegal parking in the streets of Intramuros, fourth is the improper installation of wires in Intramuros, and lastly the fifth is improper solid waste disposal in Intramuros. On the side of protect factors. Intramuros Administration's lack of restriction ranked as first, followed by Intramuros Administration's lack of ordinance in visual pollution which ranked second. then, Intramuros Administration's lack of maintenance ranked as third. Intramuros Administration's lack of security personnel ranked four; and finally, the Intramuros Administration's lack of signpost ranked last.

Inwards of preserve factors, first, the Intramuros had many infrastructures, second was the Increasing of establishments in Intramuros, third Intramuros Administration did not prioritize the preservation of the city inside the wall, fourth was there is no designated place for vendors in Intramuros, and finally the fifth is the possible modernization.

Further, in promoting factors. first, the cleanliness in the streets is a must, followed by conducting a seminar about the proper waste disposal in Intramuros, third is offering a painting activity in the community that could help them to discover their talent in art, fourth is provide livelihood program in the community in Intramuros, and the fifth is the importance of the marginalized workers in Intramuros. Hence, disseminate factors the first in the rank is providing the historical or cultural information about in Intramuros, second is safety reminder in the street of Intramuros Administration, third is giving the public notice to the tourists and community in Intramuros, 
fourth is knowledgeable about ordinance of visual pollution of the Intramuros Administration, and finally information policy of Intramuros Administration is the rank 5.

To the Intramuros Administration, disseminate and implement now the Strategy for the Effective Mainstreaming of People's Living Entitlements or the SIMPLE program, which aims to address the informal settler problem within the walled city. The program provides beneficiaries subsidized socialized housing units outside the district, amounting to P450,000/unit, which they can eventually own. This will help to lessen the human action of visual pollution inside the walled city. Various recommendations has been proposed as well such as it should make the restriction more essential, impose the guidelines to regulate a rule and policy to discipline the community inside the Intramuros, in order to maintain the cleanliness and orderliness in the area, Intramuros Administration can come up with a community-civic projects together with the local barangay, impose a solid waste management to maintain the proper disposal system inside the walled city, provide a designated area of customize booth/kiosks with generalized design exclusive to all street vendors, delivery truck should only be entered their respective establishment such as restaurants during close hours without tourists around in Intramuros, and add more signposts in the said streets and impose penalty for vandalism and loitering.

To the Department of Tourism, start to roll out the project of making the Intramuros as the sustainable creative urban heritage district which ensures a sustainable tourism industry entails a holistic management plan that starts with a great vision, and the Intramuros Administration's vision is inclusive for integrating its people's welfare, both the residents and tourists, with economic development and cultural heritage preservation to avoid the increasing cases and scenario focusing in visual pollution. The project will focus on the six priority programs slated to achieve this vision, namely, preparation and implementation of the first Intramuros' Conservation Management Plan (CMP), "pedestrianization" of the streets, Manila's Tourism Circuit, open spaces redevelopment, and the SIMPLE program or the Strategy for the Effective Mainstreaming of People's Living Entitlements.

To the local barangay unit of Intramuros, remove the unnecessary excess wires in some places in the streets so that the tourists could not put their life in danger and will not destroy the aesthetic view of the places, put the waste containers in the visible area, implement the no smoking policy inside the walled city, be more responsive by imposing strict protocols so that the subordinates will follow nor abuse their job concerning the effect of visual pollution, send at least one or two custodians in front of the San Agustin Church to look after the violators in order to avoid loitering that would make a place look bad to some other tourist.

To the businesses inside Intramuros, ensure to apply sustainability and synergy in their operation in order to maintain the beauty and heritage value of the walled city, participate in various socio-civic activity that will help the development of Intramuros, provide corporate social responsibility by simple conducting a cleanup drive, sustainable practices of taking care the sites, and ensures $100 \%$ social-economic-environmental relationship.

\section{References}

Ampler, J., Dato, K.G., Gagarin, A.J., Hugo, A.J., Jao, A., Salas, M., \& Totanes., C. (2016). Intramuros: Preserving its historical beauty. Thesis, World Citi College, Quezon City.

Barroga, S., Navarra, N., \& Palarca, H. (2020). Methodologies in identification, analysis, and measurement of visual pollution: The Case of Intramuros. https://doi.org/10.29244/jli.v13i1.33322

Dumcke, C., \& Gnedovsky, M. (2013). The social heritage and economic value of cultural heritage: Literature review.

Green, R. (1999). Meaning and form in community perception. Journal of Environmental Psychology, 19(4).

Jana, M. K., \& De, T. (2015). Visual Pollution can have a deep degrading effects on urban and sub-urban community: A Study in few places of Bengal, India, with Special Reference to unorganized billboards. European Scientific Journal.

Lloren, A., Rosset, J., \& Wueest, R. (2015). Descriptive and substantive representation of poor citizens in 
Marcelo, J., Parco, E. G., Coniendo, C. K. S., Gomez, M. L., \& Amutan, S. Y.

Switzerland.

Prompayuk, S., \& Chairatananonda, P. (2017). Historic community preservation: The approach suitable to Thai Context. Asian Social Science, 13(11).

Szczepanska, M., Wilkaniec, A., \& Skamlova, L. (2019). Visual pollution in natural and landscape protected areas: Case studies from Poland and Slovakia. https://doi.org/10.2478/quageo-2019-0041 